\title{
CHOOSING GROUNDED THEORY AND FRAME WORK ANALYSIS AS THE APPROPRIATE QUALITATIVE METHODS FOR THE RESEARCH
}

\author{
Sylesh Nechully \\ Research Scholar, UPES, Dehradun, India \\ Dr. S.K. Pokhriyal \\ Professor and Head - Energy Management, \\ School of Business - UPES, Dehradun, India
}

\begin{abstract}
The article systematically reviews various qualitative and quantitative research methods and zero in on Grounded Theory and Frame Work Analysis as the appropriate Qualitative Methods for the study
\end{abstract}

Keyword: Frame Work Analysis, Grounded Theory, Qualitative Data Analysis, Quantitative Data Analysis, Research Method

Cite this Article: Sylesh Nechully and Dr. S.K. Pokhriyal,. Choosing Grounded Theory and Frame Work Analysis as the Appropriate Qualitative Methods for the Research, Journal of Management, 6(1), 2019, pp. 130-145.

http://www.iaeme.com/jom/issues.asp?JType=JOM\&VType=6\&IType $=1$

\section{INTRODUCTION}

Data analysis is a process of examining, refining, transforming and modeling the collected data (Primary or Secondary data) with a goal of finding relevant information, finding interrelationships between information and drawing conclusions for decision makings (Shamoo and Resnik, 2003). Data analysis helps to improve business operations and enhances the bottom line of the companies (Shamoo, 1989). In simple words, data analysis is the process of Organizing, Analyzing, Extracting and Interpreting the relevant/pertinent information for decision making (Smeeton and Goda, 2003). The main objective is to find actionable insights for the problem(s) at hand (Shepard, 2002).

\section{QUANTITATIVE VS QUALITATIVE APPROACHES}

Approaches and techniques used for data analysis are classified into (1) Quantitative Analysis (2) Qualitative Analysis. Quantitative data analysis provides results which are quantifiable and easy to comprehend. Quantitative data analysis requires rational thinking from the researchers 
to draw inferences from raw numbers (Creswell, 2003). Quantitative analysis is employed either to reject or support the hypotheses formulated during the course of research. The Research design for most of the quantitative studies ensures that the personal bias is reduced to a minimum (McLeod, 2017). Quantitative Techniques are based on numbers and concrete measurable facts. Forecast can be easily made from Quantitative data. The commonly used data collection techniques in quantitative analysis are (a) Quantitative surveys - Normally close ended questions (b) Interviews (c) Quantitative Observations (d) Experiments (Treiman, 2009). Probability Sampling Techniques (All members have a chance of getting selected) are employed for selecting respondents for quantitative studies. The commonly used probability sampling techniques are (1) Random Sampling - Every member has equal chance of getting selected (2) Stratified Sampling - Population divided into strata and randomly selected (3) Systematic Sampling - Specific system like every $15^{\text {th }}$ person selected for study (4) Cluster Sampling - Population divided into clusters and clusters are randomly selected (5) Multi-Stage Random Sampling - Mix method.

Various steps in Quantitative data analysis are (1) Data Validation is a process to ensure that the data are collected according to Pre-defined research standards and with minimum or no bias. Random sampling Techniques can be used to remove or minimize the bias component. In this stage, cross checks are too performed whether the respondents were actually interviewed, the respondents were selected as per the research criteria (Screening), the data was collected as per the procedure decided (Procedure) and complete set of questions were administered to the respondents (Completeness). (2) Data Editing is the process by which the errors that might have crept in to the data are eliminated or it will hamper the data analysis. (3) Data coding is the process of grouping the responses of the respondents and assigning values to these responses. The levels of measurement or scales of measurement are determined in this step which scales to be used: Nominal, Ordinal, Interval or Ratio scale for organizing the data. (4) Quantitative Data Analysis Techniques are divided in to (a) Descriptive Statistics (b) Inferential Statistics. Descriptive statistics provides absolute numbers to summarize data. Descriptive statistics are not used when generalization from a sample to population is required. Commonly used descriptive statistics are (1) Mean (2) Median (3) Mode (4) Percentage (5) Frequency (6) Range. Mean is the average of values for a particular variable. Median is the numerical midpoint of values of a variable. Mode is the most common value of a variable. Frequency represents the number of times a particular value is found in a data set. Range refers to highest and lowest values for a variable. Percentages are used to express the set of values as a percentage of the whole. Inferential Statistics on the other hand are used to generalize results from samples to large populations. Inferential Statistics shows relationships between variables. The commonly used Inferential Statistics are (1) Correlation (2) Regression (3) Analysis of Variance (ANOVA). Correlation shows the nature of relationship between variables negative/positive/strong/weak. Regression shows to what extend one variable contributes to the occurrence of other variable. ANOVA is used to compare the means of two or more sampled groups (University of Minnesota, 2009).

The Demerit of Quantitative Techniques is that it cannot account for "Why or How" of a phenomenon. Quantitative data will not give insight(s) to the social phenomena (on). In fact qualitative data can convey the current status of things as it is - Why such things are happening cannot be inferred from Quantitative studies (Vohra, 2007).

To account for "Why or How?" of a phenomenon under study, the researcher needs Qualitative Data analysis. Qualitative data refers to non-numeric information - Texts documents, Notes, Interview Transcripts, Audio/Video Recordings and even Images. Qualitative data analysis refers to the process by which the textual data is analyzed and interpreted for various themes and patterns of relationships to understand more about the 
phenomenon under study. Qualitative analysis depends on the ability of the researcher and the context of the study. There are no rigid set of rules for data analysis. The qualitative analysis has the ability to change and adapt as the study progresses or as more and more data emerges. As the researcher analyzes more qualitative data, more patterns of interrelationships or common themes emerges. These themes and patterns helps to answer the research question and also sheds light on the direction of further data collection requirements. As the study progresses, it supports or contradicts the findings already emerged out of the qualitative analysis performed. While analyzing qualitative data, due care should be given to (1) message conveyed by the text (2) The attitude of the speaker towards the question (3) whether the experience shared is actual or hypothetical and (4) whether the ideas conveyed are that of a group or individual (Symon and Cassel, 1998).

\section{Qual Vs Quan: Basic differences}

\begin{tabular}{|c|c|c|}
\hline & Qualitative & Quantitative \\
\hline Purpose & $\begin{array}{l}\text { To describe a situation, } \\
\text { gain insight to particular } \\
\text { practice. }\end{array}$ & $\begin{array}{l}\text { To measure magnitude-How } \\
\text { widespread is a practice.. }\end{array}$ \\
\hline Format & $\begin{array}{l}\text { No pre-determined } \\
\text { response categories }\end{array}$ & $\begin{array}{l}\text { Pre-determined response } \\
\text { categories, standard measures }\end{array}$ \\
\hline Data & $\begin{array}{l}\text { li-deptic explanatory data } \\
\text { from a small sample }\end{array}$ & $\begin{array}{l}\text { Wide breadth of data from large } \\
\text { statistically representative sample }\end{array}$ \\
\hline Analysis & $\begin{array}{l}\text { Draws out patterns from } \\
\text { concepts and insights }\end{array}$ & $\begin{array}{l}\text { Tests hypotheses, uses data to } \\
\text { support conclusion }\end{array}$ \\
\hline Result & $\begin{array}{l}\text { Iliustrative explanation \& } \\
\text { individual responses }\end{array}$ & $\begin{array}{l}\text { Numerical aggregation in } \\
\text { summaries, responses are } \\
\text { dustered }\end{array}$ \\
\hline Sampling & Theoretical & Statistical \\
\hline
\end{tabular}

Figure 1 Qualitative Vs Quantitative Basic differences (adapted from Nigatu, 2009) 


\section{Qual Vs Quan: Analytic approaches}

\begin{tabular}{|l|l|l|}
\hline & Quantitative & Qualitative \\
\hline Research question & Fixed/Focused & Broader, contextual, flexible: \\
\hline Expected outcome & $\begin{array}{l}\text { Identified in } \\
\text { advance }\end{array}$ & $\begin{array}{l}\text { Usually not predefined, } \\
\text { emergent research question }\end{array}$ \\
\hline Hierarchy of phases & Linearity & Circular \\
\hline Confounding factors & $\begin{array}{l}\text { Controlled during } \\
\text { design \& analysis }\end{array}$ & Searched in the field \\
\hline Time dimension & Slower & Rapid to slower \\
\hline
\end{tabular}

Figure 2 Qualitative Vs Quantitative Analytical approaches (adapted from Nigatu, 2009)

\section{Qual Vs Quan: Data collection method}

\begin{tabular}{|l|l|l|}
\hline & Quantitative & Qualitative \\
\hline Sampling & Random sampling & $\begin{array}{l}\text { Open ended and less structured } \\
\text { protocols (Flexible) }\end{array}$ \\
\hline Tools & $\begin{array}{l}\text { Structured data } \\
\text { collection instruments }\end{array}$ & $\begin{array}{l}\text { Depend on interactive } \\
\text { interviews }\end{array}$ \\
\hline Results & $\begin{array}{l}\text { Produce results that } \\
\text { generalize, compare and } \\
\text { summarize }\end{array}$ & $\begin{array}{l}\text { Produce results that give } \\
\text { meaning, experience and views }\end{array}$ \\
\hline
\end{tabular}

Figure 3 Qualitative Vs Quantitative Data Collection Method (adapted from Nigatu, 2009)

The steps involved in Qualitative data analysis are (1) the collected data should be processed and recorded immediately. The researcher's thoughts and opinion about the collected data along with the time, data and location of data collection are to be noted. Any information worthy of getting highlighted should not be omitted. (2) The data should be analyzed as and when it is collected so that the researcher can search for the recurring themes and patterns in the 
subsequent data analysis. As the researcher proceeds with qualitative data analysis, a frame work or conceptual lens emerges which gives the researcher further direction for data collection and analysis. (3) Next step is data reduction where the researcher goes through volumes of data and identifies the relevant data for study. Research questions along with the conceptual lens or frame work that emerged from the initial analysis helps to isolate the relevant data for the study. (4) The data should be grouped to patterns of relationships and Themes (Pope and Mays, 2000). This is done by (a) Content Analysis (b) Thematic Analysis. In content analysis, the researcher goes through the data and codes the relevant data using words or symbols and looks for patterns of interrelationship using codes. Themes are pre-set or arise naturally from qualitative data analysis. The grouping of data into themes helps to go deeper into the research problem. A code (Short phrase or Word) represents an Idea or Concept or Theme. Categorization of data is done using codes. There are three types of coding in Qualitative analysis - Open coding, Axial coding and Selective coding. Open coding is the process of organizing data in to codes. Axial coding is the process of linking and interconnecting various categories of codes. Selective coding is the process of developing stories connecting these categories. In fact the coding process in a qualitative analysis can be considered as an iterative process which stops only when a story line/ or answer or conclusion is reached.

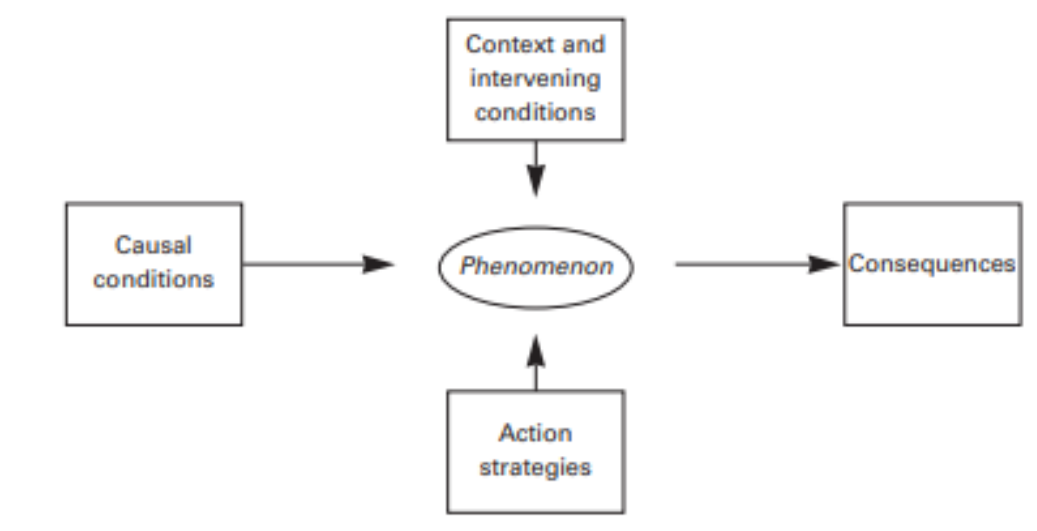

Coding paradigm for social science research questions

Figure 4 Coding Paradigm for Social Science Research Questions (adapted from Bohm, 2004)

Codes or categories of codes are revisited many times for getting deeper insights to the phenomenon/research question under study. Coding can be done manually or using software. Manual coding is a very tedious process and nowadays the coding is done using software like NVIVO, Atlas ti or Max QDA (Crossman, 2017). (5) Data display is a process of arranging Themes or Patterns using tables, graphics or simply textual display for drawing inferences. (6) Drawing the conclusions from the data display and verifying the conclusions constitutes the last step of qualitative analysis. The researcher needs to verify whether the conclusions or findings answer the research questions. This can be done by analyzing new qualitative data or by revisiting the existing analysis multiple times (Gibson, Timlin and Curran, 2004).

The commonly used data collection methods in Qualitative study are (1) Interviews Structured, Semi Structured and In -Depth (Commonly used) (2) Focus Group (3) Observational methods (4) Document Analysis.

Qualitative studies use Non Probability Sampling (Bias is a problem to be tackled since random selection is not employed) to select respondents. Commonly used Non Probability Sampling Techniques are (1) Convenience Sampling - Respondents selected based on availability (2) Judgment Sampling - Purposeful Selection (3) Expert Sampling - Experts on the Topic included as respondents (4) Diverse Sampling - Respondents selected from diverse 
back ground to comprehend the nature of all possible responses (5) Quota Sampling Respondents are sampled till sufficient data are collected for particular categories (6) Snow ball sampling - The respondents selected for study are asked to identify other respondents having characteristics relevant for the study (Byrne, 2017).

The commonly used research designs for qualitative analysis are (1) Phenomenology Study of phenomenon as experienced by the individuals - in simple words, the study of "How" individuals experience things. Each individual is unique and this uniqueness is reflected in the way the individuals interpret experiences. The Reality is a subjective concept. (2) Grounded Theory - Develops theory from data inductively (3) Ethnography - Study of characteristics of people and cultures - customs, habits, similarities and differences. Usually Participant observation method is employed for data collection. (4) Participatory action research Researcher analyzes their own experiences in research settings. (5) Case Study - Investigation of events/real life situations or individuals or group of individuals for making inferences. Normally case study method answers the question of How or Why? (Bernad, 1995)

\section{Common qualitative study designs}

\begin{tabular}{|l|l|}
\hline Study design & Description \\
\hline Ethnography & $\begin{array}{l}\text { Portrait of people-study of the story and culture of a } \\
\text { group usually to develop cultural awareness \& } \\
\text { sensitivity }\end{array}$ \\
\hline Phenomenology & $\begin{array}{l}\text { Study of individual's lived experiences of events-e.g. the } \\
\text { experience of AIDS care }\end{array}$ \\
\hline Grounded theory & $\begin{array}{l}\text { Going beyond adding to the existing body of } \\
\text { knowledge-developing a new theory about a } \\
\text { phenomenon-theory grounded on data }\end{array}$ \\
\hline $\begin{array}{l}\text { Participatory action } \\
\text { research }\end{array}$ & $\begin{array}{l}\text { Individuals \& groups researching their own personal } \\
\text { beings, socio-cultural settings and experiences }\end{array}$ \\
\hline Case study & $\begin{array}{l}\text { In-depth investigation of a single or small number of } \\
\text { units at a point fover a period) in time. E.g. Evaluation of } \\
\text { s service }\end{array}$ \\
\hline
\end{tabular}

Figure 5 Common Qualitative Study Designs (adapted from Nigatu, 2009)

The main focus of questions in qualitative analysis should be to collect and analyze the experiences, feelings, opinions and other relevant inputs from people with an objective to gain more knowledge on the research topic.

Various types of Qualitative questions are summarized in the Figure (6) 


\section{Questions for qualitative interviews}

\begin{tabular}{|c|c|}
\hline $\begin{array}{l}\text { Types of } \\
\text { questions }\end{array}$ & Examples \\
\hline Hypothetical & $\begin{array}{l}\text { If you get the chance to be an HIV scientist, do you think } \\
\text { you can discover a vaccine for HIV? }\end{array}$ \\
\hline Provocative & $\begin{array}{l}\text { I have heard people saying most evaluations are } \\
\text { subjective-what do you think? }\end{array}$ \\
\hline Ideal & $\begin{array}{l}\text { In your opinon, what would be the best solution for } \\
\text { eliminating gender-based violence? }\end{array}$ \\
\hline Interpretative & What do you mean by good? \\
\hline Leading: & Do you think prevention is better than cure? \\
\hline Loading & $\begin{array}{l}\text { Do you watch that culturally degrading TV show on } \\
\text { condom use? }\end{array}$ \\
\hline Multiple: & $\begin{array}{l}\text { Tell me y out three favourite authors, the book you like } \\
\text { best by each author, and why you tike those books? }\end{array}$ \\
\hline
\end{tabular}

Figure 6 Question for Qualitative Interviews (adapted from Nigatu, 2009)

The main disadvantages of Qualitative data analysis are (1) Researcher bias can have an impact on the qualitative data collected (2) The quality of data collected depends on the skills and experience of the researcher (3) The findings of qualitative analysis are very valuable on most occasions but very difficult to present (4) Replication of results are difficult in qualitative studies (Nigatu, 2009).

\section{NARROWING DOWN ON THE QUALITATIVE APPROACH}

The research objectives for the Researcher's study are formulated as (1) To find out the different variables than can influence the adoption of innovative drilling technologies in Upstream UAE Oil \& Gas. (2) To propose a Framework (covering the entire gamut of Technology adoption with special emphasis to Pre-adoption) to facilitate/enhance the adoption of innovative drilling technologies in Upstream UAE Oil \& Gas.

So the researcher needs to identify why it is slow and how adoption of innovative drilling technologies can be enhanced in upstream oil and gas. "Why" and "How" of a phenomenon like adoption cannot be studied using Quantitative techniques. So the researcher decides to use Qualitative approach for the study.

Qualitative Data Analysis can be broadly divided in to (1) Content Analysis (2) Narrative Analysis (3) Discourse Analysis (4) Grounded Theory (5) Frame Work Analysis.

Content analysis is used to study the recorded information (Media and Texts). It can also be defined as the process of systematically analyzing the text, images or any recorded material either from the perspective of the author or analyst. It does not require data collection from the respondents (Columbia University, 2016). Content analysis is also used to identify the presence and relationships of themes or concepts with in the texts. The texts are broken down to "Codes" and these "Codes" can be further broken down or merged to "Categories of codes" till the researcher develops a conclusion or story line around a "Core category". Content Analysis is of two types (1) Conceptual - Determines the presence and frequency of concepts in a text (2) Relational - Identifies the relationships between concepts with in the text.

Discourse analysis refers to the study of how people use language - both in its written and spoken form between themselves. Discourse analysis studies the real running conversation verbal or written between real speakers in real contexts. Discourse analysis goes beyond the sentences spoken or written but the contexts in which those sentences are written or spoken are 
also taken in to account while interpreting verbal or written sentences during analysis (Adolphus, 2018). The context modifies "What is intended to convey" in sentences/messages. Situational factors - Social/Political/Economic factors and Professional affiliations modifies the meanings of the words written or spoken.

Narrative Analysis is the process by which the respondents are encouraged to tell stories about the "Research Phenomenon" or relevant stories about the Phenomenon are identified from the existing literature and these stories are analyzed to get insights to the phenomena(on) under study. The contexts of those stories are also to be taken into account while doing analysis. Narrative analysis helps to understand how people interpret various situations, experiences or phenomena under different contexts. The researcher can make generalizations about the phenomena (on) under study from the stories of the respondents.

Grounded theory is the process of generating theory by analyzing the qualitative data collected. The Theory is grounded in the data collected. In grounded theory the data collection and analysis is done simultaneously. Data collected can be qualitative or quantitative. Focus group, In-depth interviews using open ended questions and other observational methods are used for data collection. There are controversies whether the researcher should start off the data collection with preconceived theoretical assumptions or not. Glaser was against using theoretical assumptions whereas Strauss and Corbin supported this approach. Strauss and Corbin supported the use of Pre-Determined categories of codes or Questions to make the data collection and analysis easier rather than keeping an open approach and waiting for the codes or concepts to emerge naturally from data. The researcher modifies the existing questions and adds news questions as the theory emerges from the data analysis. Grounded theory is a data analysis technique which helps the researcher to unravel the hidden patterns of relationships and to construct theories in the area of study. The grounded theory guides a researcher as to where to look for additional details/information for construction of theories. As the data analysis progresses - initial concepts, ideas or codes emerges. Further data is collected and analyzed to support or refute these initial findings.

Theoretical sampling is a process by which the researchers collect the required data from relevant sources to support or refute the initial categories, concepts or ideas and relationship patterns proposed by the previous studies. The data collection and analysis stops when no new ideas, concepts or codes emerge - by principle of saturation (Noble and Mitchell, 2016).

\section{Sampling in Qualitative research}

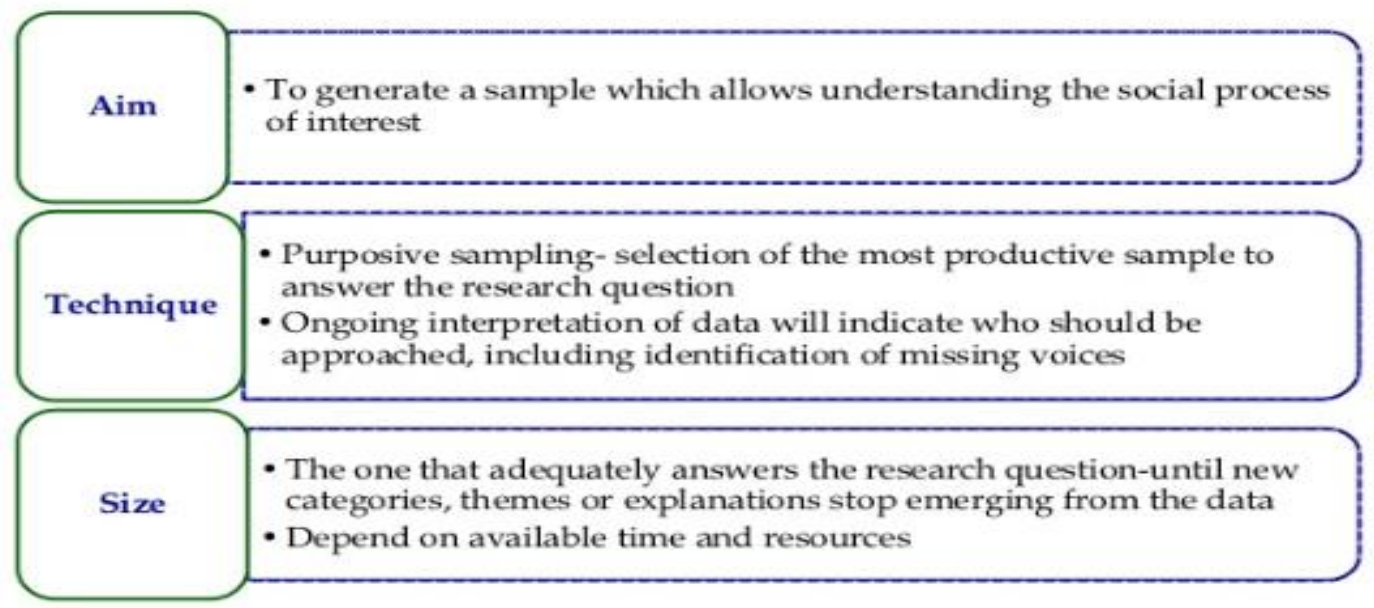

Figure 7 Sampling in Qualitative Research (adapted from Nigatu, 2009) 
Theoretical sensitivity refers to the ability of a researcher to develop insights from the analyzed data. These insights helps researcher to develop the theory from the data. Theoretical sensitivity comes from (1) Literature review (2) Professional Experiences (3) From the process of data collection itself. The data from participants are often compared and contrasted. The data analysis is done in three steps (1) Open coding (2) Axial coding (3) Selective coding.

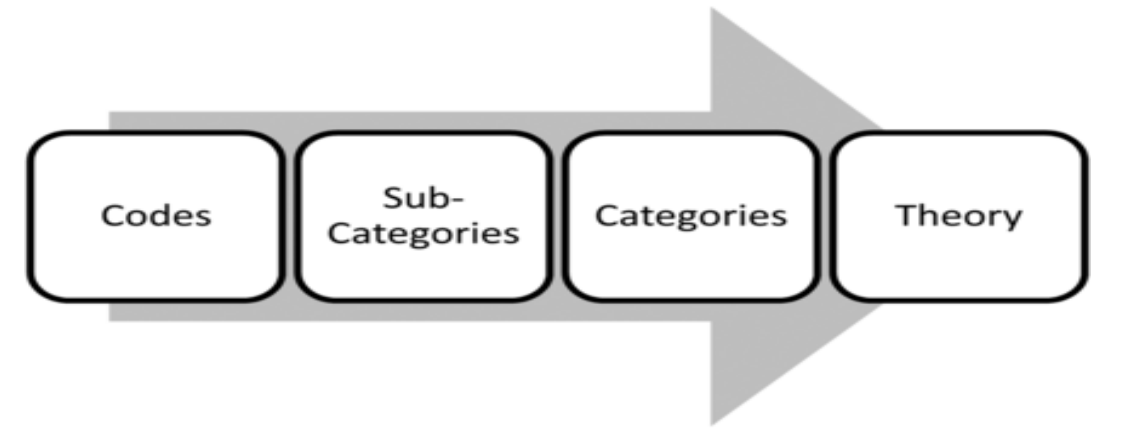

Figure 8 Grounded Theory Data Analysis (adapted from Noble and Mitchell, 2016)

Analytical Memos are used to note down or highlight important insights or anything that is important to the study. These analytical memos are expanded and integrated to generate the theory. Open coding breaks the data into categories of codes. Axial coding helps the researcher to find the relationships between these categories and Selective coding helps the researcher to find a Core category to which all other categories can be connected to develop the theory.

\begin{tabular}{|c|c|}
\hline Stage & Purpose \\
\hline Codes & Identifying anchors that allow the key points of the data to be gathered \\
\hline Concepts & Collections of codes of similar content that allows the data to be grouped \\
\hline Categories & Broad groups of similar concepts that are used to generate a theory \\
\hline Theory & A collection of categories that detail the subject of the research \\
\hline
\end{tabular}

Figure 9 Codes, Concepts, Categories and Theory (adapted from Noble and Mitchell, 2016)

The classic grounded theory proposed by Glaser analyses the data collected to find out the research problem in a particular area of interest whereas the grounded theory proposed by Strauss and Corbin starts with data collection to find solution for a known problem. Glaser proposed to keep an open approach while Strauss and Corbin proposed to have predefined codes and categories for data analysis. Strauss and Corbin proposed a detailed literature review to get insights to the area of study and analysis started with preconceived questions. The classic grounded theory has only two steps. The first step is to break down data into what is called in Classic Grounded Theory as "Substantive Codes" and the process is continued by comparing data for similarities and differences till the "Core category" category emerges. The second step is "Theoretical coding" - the process by which all the codes and categories of codes are connected/related to the core category for developing theory (Babbie, 2010). Theoretical coding is not a part of Strauss and Corbin's version of grounded theory. In fact, Theoretical codes also emerge from data analysis and provide a relational model for connecting codes and categories to the core category (Hernandez, 2009). Substantive codes break down the data while Theoretical codes bring the broken parts together to form a theory. Theoretical coding is done during the analysis and integration of memos. Reviewing memos help to connect Substantive codes to the core category. Many theoretical codes emerge during GT, however the theoretical codes that connects all substantive codes emerges only after the emergence of core category. As the theoretical codes simply convey the relationships between two or more substantive codes 
or categories, It is imperative to identify an Ultimate Theoretical code that integrates all relationships to formulate a theory or generalization (Bohm, 2004). Glaserian and Straussian versions of grounded theory are different approaches of Grounded Theory and utmost care has to be taken to apply either one of these methods. Glaser (2015) emphasizes that the Grounded Theory is only "Inductive" in nature but Strauss and Corbin (1998) contradicts this by emphasizing the need to make deductions and validate the theories. Strauss emphasizes the need for Induction, Deduction and Validation steps in grounded theory. The validation is the process of applying the preconceived codes or categories or interrelationships concepts against the data and testing how well they stand up to that scrutiny. Strauss and Corbin (1990) employed a process called "Abduction" where the theories or hypothesis formed in the initial analysis by induction or preconceived are validated against the data by deduction process. Other versions of Grounded theory are Constructivist grounded theory and Critical Realist grounded theory. Constructivist grounded theory assumes that the theories are not discovered but constructed together by the Researcher and the respondent and is influenced by the Researcher's values, perspectives, locations, positions etc (Charmaz, 1990).

Frame work analysis as a qualitative data analysis method is suitable when the researcher has a priori issues, predefined questions to get solutions/answers to those issues, limited time and known sources of data collection (Ward, et al., 2013). It helps the researcher to analyze and interpret the actual events or happenings in a particular context or setting. Frame work analysis can answer questions belonging to four broad categories.

\begin{tabular}{|c|c|c|}
\hline Category & Goal & Sample questions \\
\hline Contextual & $\begin{array}{l}\text { dentifying the form and natur } \\
\text { what exists }\end{array}$ & $\begin{array}{l}\text { What are the dimensions of attitudes or percept } \\
\text { hat are held? } \\
\text { What is the nature of people's experiences? } \\
\text { What needs and does the population of the s } \\
\text { have? } \\
\text { What elements operate within a system? }\end{array}$ \\
\hline Piagnostic & $\begin{array}{l}\text { Examining the reasons for, or ca } \\
\text { f, what exists }\end{array}$ & $\begin{array}{l}\text { What factors underlie particular attitudes } \\
\text { perceptions? } \\
\text { Why are decisions or actions taken, or not taken? } \\
\text { Why do particular needs arise? } \\
\text { Why are services or programs and not been used? }\end{array}$ \\
\hline Evaluative & $\begin{array}{l}\text { Appraising the effectiveness of } \\
\text { exists }\end{array}$ & $\begin{array}{l}\text { How are objectives achieved? } \\
\text { What affects the successful delivery of program } \\
\text { ervices? } \\
\text { How do experiences affect subsequent behaviour } \\
\text { What barriers exist to systems operating? }\end{array}$ \\
\hline Strategic & $\begin{array}{l}\text { dentifying new theories, pol } \\
\text { lans or actions }\end{array}$ & $\begin{array}{l}\text { What types of services are required to meet needs } \\
\text { What actions are needed to make program } \\
\text { pervices are more effective? } \\
\text { How can systems be improved? } \\
\text { What strategies are required to overcome the n } \\
\text { lefined the problems? }\end{array}$ \\
\hline
\end{tabular}

Figure 10 Research Categories and Questions (adapted from Ritchie and Spencer, 1994)

The data for Frame work analysis are collected through Interviews, Participant observation and Focus groups. Interviews are of three types - Structured, Unstructured and Semi-Structured Interviews (McCracken, 1988). For Frame work analysis, Semi structured interviews are most preferred method of data collection since the questions are predefined and if additional details are required the researcher has the freedom to deviate from the structured pattern of questions (Abbarker, 2016)

Frame work analysis facilitates the validation of Theories/Concepts/Ideas at various stages of analysis using mix methods. The research design proposed by Ritchie and Spencer has four stages of refinements/validations and in the first two stages - Content analysis/Document 
Analysis is used and the last two stages - Grounded theory is used. Frame work analysis starts off with a preliminary conceptual lens (Ritchie and Spencer, 1994).

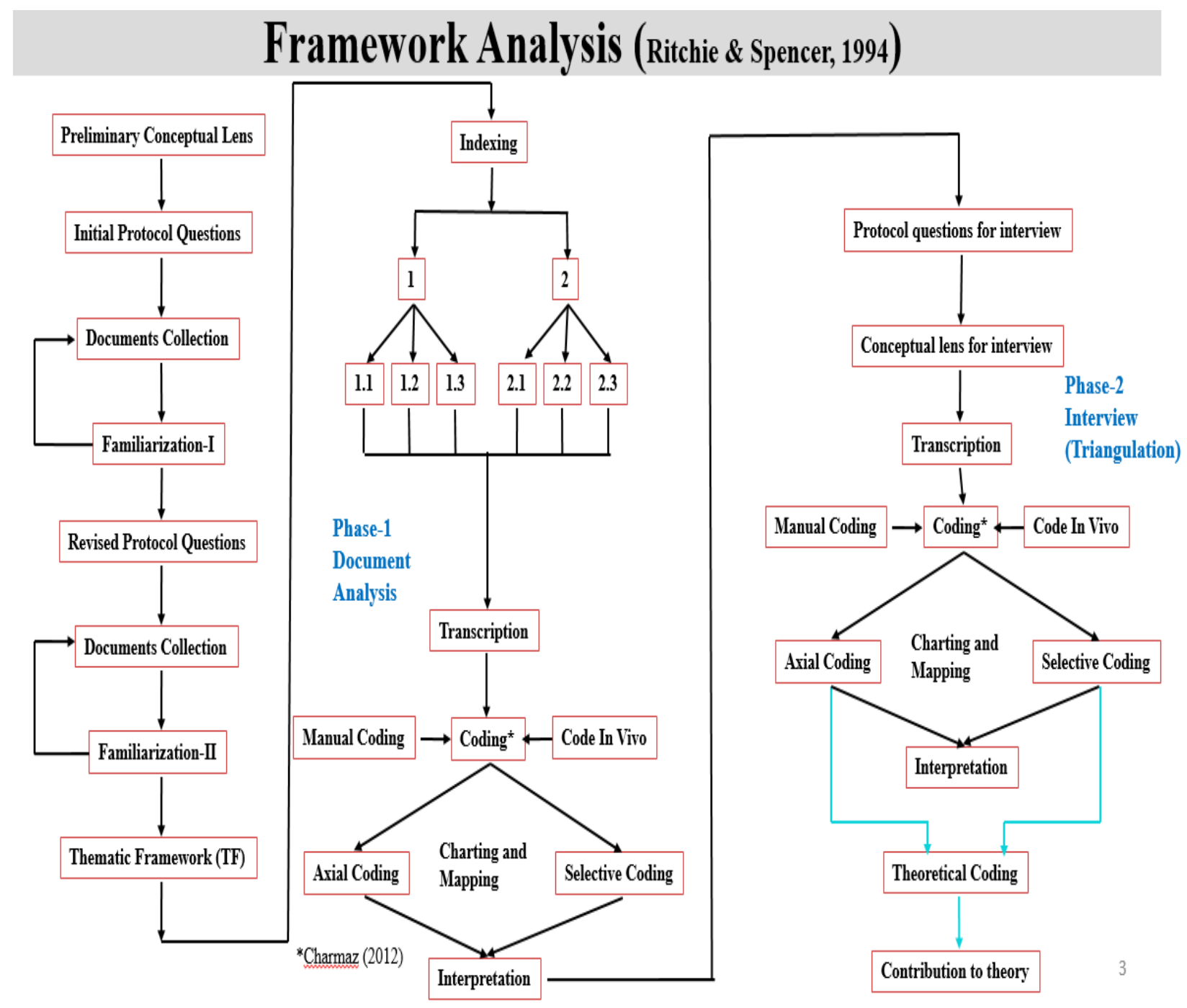

Figure 11 Frame Work Analysis (adapted from Ritchie and Spencer, 1994)

Frame work analysis gives the flexibility to the researcher to do the data collection and analysis simultaneously or after the collection of data. The researcher does not have to analyze the volumes of data collected. Instead the researcher can stop once all the information pertaining to the research question has been collected. The researcher needs to analyze the relevant portions of the data only. Authors differ in the number of stages of validation required for Frame work analysis. At every stage of analysis the conceptual/thematic frame work is refined and validated. Frame work analysis employs a deductive approach for analysis - For general to particular. The themes/codes or categories are predefined in Frame work Analysis. In Frame work analysis, like in grounded theory the data are compared for similarities and differences constantly. A frame work helps to arrange data into a matrix of rows and columns. Rows represent the respondents/focus groups and columns represent the themes or concepts. Software likes NVIVO, Atlas ti etc are used for Frame work analysis.

The steps followed for Frame work analysis are (1) Transcription of data (2) Familiarization with the qualitative data collected (3) Coding of data - Either Deductive or Inductive approach. In deductive approach the codes and categories will be predefined. In Inductive approach - the codes or categories emerge from the data - an open approach (4) Construction of a 
working/tentative analytical frame -work from the codes (5) Applying this tentative frame work to the collected data or data going to be collected (6) Charting the data into the Frame work matrix (7) Analyzing and Interpreting the data (Srivastava and Thomson, 2009).

The Frame work gets refined and validated at different stages of analysis. Frame work analysis allows people from diverse back ground to work on the same project. The Charting facility provides the researchers to stop for breaks and to restart from where they left. Frame work analysis is widely used in social policy research and health/medical sciences. Epistemological stance of the researcher influences Frame work analysis.

\section{NARROWING DOWN ON GROUNDED THEORY AND FRAME WORK ANALYSIS AS APPROPRIATE QUALITATIVE METHODS}

The next step of the researcher is to find a suitable method for qualitative study. For research objective (1) the researcher has to identify the relevant variables affecting adoption in upstream UAE Oil and Gas. The researcher can find the relevant variables by interviewing the end users in upstream oil and gas or by conducting a focus group and subsequent coding. But due to nonavailability of end users at a common venue, the researcher narrows down to data collection by Interviews. Our next step is to determine the "structure" of the interview. The process of unraveling the relevant variables by In-depth interviews/Unstructured interviews is a time consuming process. The researcher prefers to have some flexibility. So the researcher decides on "Semi-Structured" form of interview. Now the researcher needs to determine the relevant questions to be asked. These questions can be derived from the literature review of similar studies done in different industries/regions. It is always advisable to frame the questions from a conceptual lens or preliminary thematic frame work - which can be made from the literature review. The approach suggested by Glaser - Open approach without any preconceived ideas or questions or without any literature review is a very time consuming / tedious process. Strauss and Corbin and later Charmaz recommend using preconceived codes or questions for qualitative analysis. The collected data is analyzed by coding technique - Open, Axial and Selective coding. The process of data collection using semi-structured interview and analysis using coding techniquede is nothing but grounded theory. The codes generated are connected together to generate a theory. Theory is grounded in the data collected. To conclude with for Research objective one - the researcher uses Grounded Theory (Strauss and Corbin Version) - Semi structured interview followed by Coding. Even though the researcher is using pre-conceived codes or questions or a preliminary frame work, the researcher's experience in the industry or expertise in the subject should not create any bias during data collection and analysis stage. Data should not be purposefully manipulated to support the preliminary assumptions/codes or frame work. Researcher should have an "open mindset" while collecting and analyzing data.

For Research Objective 2, the researcher needs to propose a frame work to enhance the adoption. To create a frame work, first the researcher needs to study the process of adoption in detail - various stage of adoption and then the researcher needs to fit in the variables from Research Objective one to relevant stages of adoption. The process of coding - open, axial and selective coding for Research objective one creates a frame work of variables - which can be used as a Preliminary Frame work/Conceptual Lens for Research Objective two. The researcher requires a systematic time bound data collection and analysis from the end users in the upstream oil and gas to propose a frame work and the frame work has to be validated several times before being presented to the research community/industry. Considering the above facts, a suitable research method for the Research Objective two will be Frame Work Analysis. In the Frame work analysis, Researcher start off with a conceptual lens or Preliminary frame work and this Frame work gets refined/modified and validated several times during different stages of 
analysis. Content Analysis can be used in the first two stages and subsequently Grounded theory (Strauss and Corbin's Version) can be used in the last two stages.

The use of Grounded Theory for Research Objective one adds an element of Redundancy into Qualitative analysis. Frame Work Analysis gives answers to both Research Objectives One and Two. This step is intentionally added by the researcher for Pilot testing of the interview schedule as well as to include only the "Industry specific Variables" - what the researcher prefers to call as "Oil and Gas Preliminary Frame Work". The conceptual lens is customized to Oil and Gas. The conceptual lens is given an Oil and Gas orientation by doing analysis using grounded theory. This "Oil and Gas Preliminary Frame Work" goes as an input to Research Objective two for further refinements and validations.

\section{SAMPLE SIZE FOR QUALITATIVE STUDY}

For qualitative studies, Patton (2002) suggests that the best sample size depends on time allocated, resource available, study objectives and ease of access. Creswell (2003) recommends 5 to 25 and Morse (1994) at least 6. Glaser and Strauss (1967) suggests to follow the "Principle of saturation" to determine the sample size for qualitative study - that is saturation occurs when adding one more respondent will not contribute any further dimension or information for the study. Malterud, Siersma and Guassora (2015) propose the concept of "Information power" to determine the sample size for qualitative study. Information power indicates that "the more information the sample holds, relevant for study, the lower amount of participation is needed". Sample size with sufficient information depends on (1) aim of study (2) quality of dialogue (3) sample specificity (4) analysis strategy. Guest, Bunce and Johnson (2006) suggest that saturation often occurs in a homogenous group around 12 participants. Latham (2003) states that around 15 participants - the saturation occurs. Crouch and McKenzie (2006) proposes that the "Sweet Spot" for qualitative research is 15 to 20 homogenous participants.

\section{QUALITY IN QUALITATIVE STUDY}

Ultimately, the qualitative study is done on a research problem and the findings are presented but the researcher cannot use the conventional criteria of reliability, validity and empirical generalizability of quantitative analysis to Qualitative study to assess the Quality of the work. To assess the Quality of Qualitative study, the work has to meet the criteria of (1) Credibility Whether the conclusions are meaningful and presented in a well-defined manner (2) Rigor Appropriateness of the methods selected (3) Reflexivity - The effects of researcher's views and methods on data (4) Transferability - Application of findings to similar context. 
Choosing Grounded Theory and Frame Work Analysis as the Appropriate Qualitative Methods for the Research

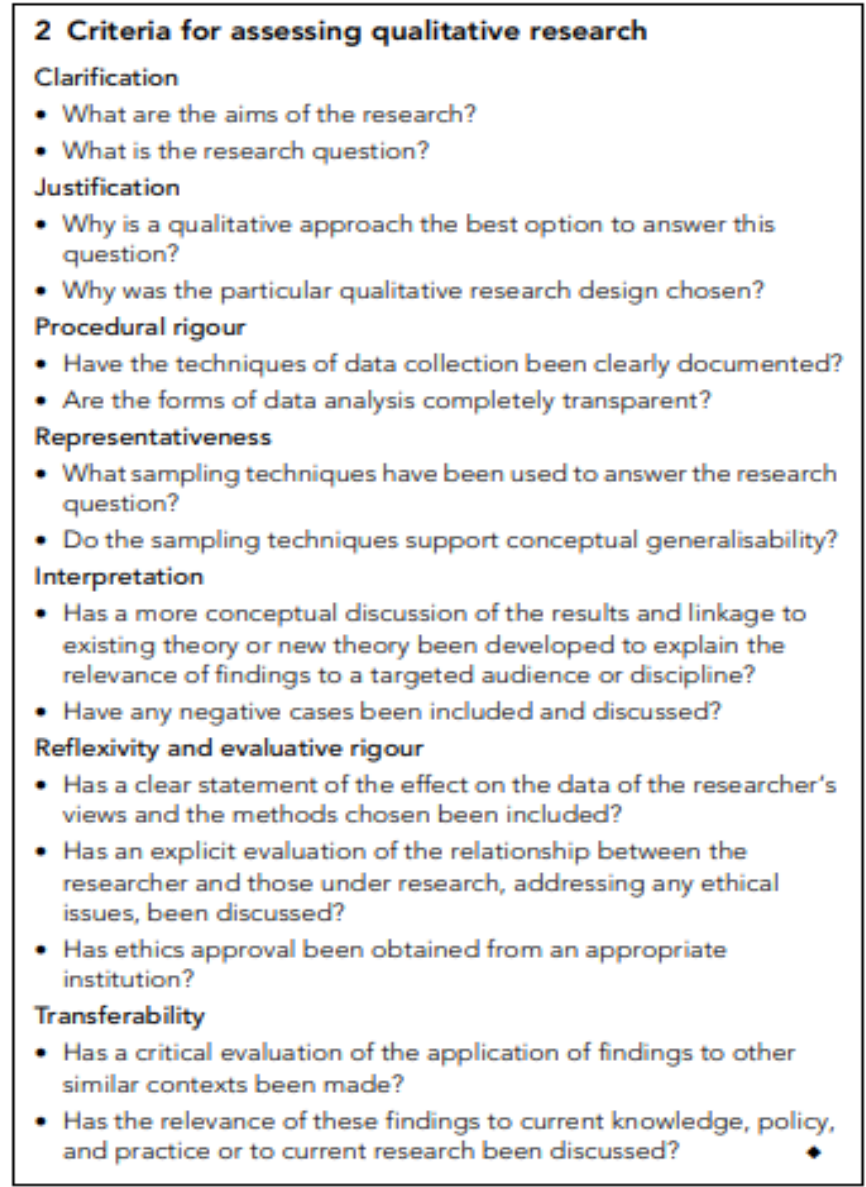

Figure 12 Quality in Qualitative Research (adapted from Kitto, Chesters and Grbich, 2009)

Detailed requirements for assessing the Quality of Qualitative work is given in the above Figure 12. It is highly recommend to use this table as a check list to make the sure all aspects of Qualitative works are thoroughly checked - it can be done during the course of research stages as and when the researcher completes particular stages of research or it can be rechecked once the work is finished completely.

\section{CONCLUSION}

So to conclude with, For Research Objective one - The Researcher uses Grounded Theory (Semi-Structured Interview followed by Coding) and For Research Objective two - Researcher uses Frame Work Analysis.

\section{REFERENCES}

[1] Abbarker, The framework method of qualitative data presentation and analysis. [online] Available at: $<$ https://abbarker.wordpress.com/2016/08/10/the-framework-method-ofqualitative-data-presentation-and-analysis/> [Accessed 10 November 2018], 2016

[2] Adolphus, M., How to use discourse analysis? [online] Available at: < http://www.emeraldgrouppublishing.com/research/guides/methods/discourse_analysis.htm $>$ [Accessed 10 October 2018], 2018

[3] Babbie, E. R., The Practice of Social Research. Belmont, CA: Wadsworth Cengage, 2010

[4] Bernard, H.R., Research Methods in Anthropology. London: Sage Publications, 1995 
[5] Bohm, A., Theoretical Coding: Text Analysis in Grounded Theory. In: U. Flick, E. Kardorff and L. Steinke, eds. 2004. A Companion to Qualitative Research. London: Sage Publications, 2004, pp. 270-275

[6] Byrne, D., Data Analysis and Interpretation. [online] Available at: $<$ http://methods.sagepub.com/project-planner/data-analysis-andinterpretation?fromsearch=true > [Accessed 02 January 2019] , 2017

[7] Charmaz, K, Discovering chronic illness: Using grounded theory. Social Science and Medicine, 30, 1990, pp. 1161-72

[8] Columbia University, Content Analysis. [online] Available at: <https://www.mailman.columbia.edu/research/population-health-methods/contentanalysis> [Accessed 15 December 2018], 2016

[9] Creswell, J. W., Research design: Qualitative, quantitative and mixed methods approaches. Thousand Oaks, CA: Sage Publications, 2003

[10] Crossman, A., An Overview of Qualitative Research Methods. [online] Available at:< https://www.thoughtco.com/qualitative-research-methods-3026555> [Accessed on 03 February 2019], 2019

[11] Crouch, M. and McKenzie, H., The logic of small samples in interview-based qualitative research. Social Science Information, 45(4), 2006, pp. 483-499

[12] Gibson, G., Timlin, A. and Curran S.,The scope for qualitative methods in research and clinical trials in dementia. Age Ageing, 33, 2004, pp. 422-426

[13] Glaser, B. G. and Strauss, A. L, The discovery of grounded theory: Strategies for qualitative research. New York: Aldine de Gruyter, 1967

[14] Glaser, B. G, The grounded theory perspective III: Theoretical coding. Mill Valley, CA: Sociology Press, 2005

[15] Guest, G., Bunce, A., and Johnson, L, How Many Interviews Are Enough?: An Experiment with Data Saturation and Variability. Field Methods, 18(1), 2006, pp. 59-82.

[16] Hernandez, C. A, Theoretical coding in Grounded Theory Methodology. [online] Available at: $<$ http://groundedtheoryreview.com/2009/11/30/theoretical-coding-ingrounded-theory-methodology/> [Accessed 10 November 2018], 2009

[17] Kitto, S. C., Chesters, J. and Grbich, C, Quality in Qualitative Research: Criteria for authors and assessors in the submission and assessment of qualitative research articles for the Medical Journal of Australia. Medical Journal of Australia, 188, 2008, pp. 243-246

[18] Latham, A, Research, Performance, and Doing Human Geography: Some Reflections on the Diary-Photograph, Diary-Interview Method. Environment and Planning A: Economy and Space, 35(11), 2003, pp. 1993-2017

[19] Malterud, K., Siersma, V.D. and Guassora, A.D, Sample Size in Qualitative Interview Studies: Guided by Information Power. Qualitative Health Research, 26, 2015, pp. 17531760 .

[20] McCracken, G, The long interview. Thousand Oaks, CA: Sage Publication, 1988

[21] McLeod, S., 2017. Qualitative Vs Quantitative Research. [online] Available at: < https://www.simplypsychology.org/qualitative-quantitative.html> [Accessed on 19 January 2019]

[22] Morse, J, Designing Funded Qualitative Research. In: N. Denzin, and Y. Lincoln, eds. 1998. Strategies of Qualitative Inquiry. Thousand Oaks, CA: Sage Publication, 1998, pp. 56-85.

[23] Nigatu, T., Qualitative Data Analysis. [online] Available at: <https://www.slideshare.net/tilahunigatu/qualitative-data-analysis-11895136> [Accessed 01 January 2019], 2009 
Choosing Grounded Theory and Frame Work Analysis as the Appropriate Qualitative Methods for the Research

[24] Noble, H. and Mitchell, G, What is grounded theory? Evidence-Based Nursing, 19(2), 2016, pp. 34-35.

[25] Patton, M. Q, Qualitative research and evaluation methods. Thousand Oaks, CA: Sage Publications, 2002

[26] Pope, C. and Mays, N, Qualitative Research in Health Care. London: BMJ Books, 2000

[27] Ritchie, J. and Spencer, L, Qualitative data analysis for applied policy research. In A.Bryman and R. G. Burgess, eds. 1994. Analyzing qualitative data. London: Routledge, 1994, pp. 173-194

[28] Shamoo, A. E. and Resnik, B. R., Responsible Conduct of Research. Oxford, UK: Oxford University Press, 2003

[29] Shamoo, A. E., Principles of Research Data Audit. New York: Gordon and Breach, 1989

[30] Shepard, R. J, Ethics in Exercise Science Research. Sports Med, 32(3), 2002, pp. 169-183.

[31] Smeeton, N. and Goda, D, Conducting and Presenting Social Work Research: Some Basic Statistical Consideration. Br J Soc Work, 33, 2003, pp. 567-573.

[32] Srivastava, A. and Thomson, S.B, Framework Analysis: A Qualitative Methodology for Applied Policy Research. JOAAG, 4(2), 2009

[33] Strauss, A. and Corbin, J, Basics of qualitative research: grounded theory procedures and techniques. Thousand Oaks, CA: Sage Publications, 1990

[34] Strauss, A., and Corbin, J, Basics of qualitative research: Techniques and procedures for developing grounded theory. Thousand Oaks, CA: Sage Publications, 1998

[35] Symon, G. and Cassel, C, Qualitative methods and analysis in organizational research. Thousand Oaks, CA: Sage Publications, 1998

[36] Treiman, D.J, Quantitative Data Analysis: Doing Social Research to Test Ideas. San Francisco: John Wiley and Sons, 2009

[37] University of Minnesota, Qualitative or Quantitative date? [online] Available at:< https://cyfar.org/qualitative-or-quantitative-data> [Accessed 07 February 2019], 2009

[38] Vohra, N. D, Quantitative Techniques in Management. New Delhi: Tata Macgraw-Hill, 2007

[39] Ward, D.J., Furber, C., Teierney, S. and Swallow, V, Using Framework Analysis in nursing research: a worked example. Journal of Advanced Nursing, 69(11), 2013, pp. 2423-2431 